\title{
Density Functional Theory Study of 2,1,3-Benzoxadiazole-5- Carboxylic Acid as Photosensitizers for Dye-sensitized Solar Cells
}

\section{SATHYANARAYANA MOORTHI ${ }^{1 *}$, J.PRAKASH MANUEL JOE² and S.MOHAN KUMAR ${ }^{2}$}

\author{
'Department of Physics, PSG College of Arts and Science, Coimbatore - 641 014, India. \\ 2Department of Electronics, PSG College of Arts and Science, Coimbatore - 641 014, India. \\ ${ }^{*}$ Corresponding author E-mail: sathyanarayanamoorthi@yahoo.co.in
}

http://dx.doi.org/10.13005/ojc/310116

(Received: January 10, 2015; Accepted: February 09, 2015)

\section{ABSTRACT}

\begin{abstract}
Theoretical analysis of the 2,1,3-Benzoxadiazole-5-carboxylic acid dye molecule and new designed dyes were performed using Density Functional Theory. The ground state and excited state oxidation potential as well as electron injection from dyes to $\mathrm{TiO}_{2}$ are reported. Improved light harvesting efficiency and free energy change of electron injection of new designed sensitizers reveal that these materials would be excellent sensitizers. This theoretical designing will pave way for the experimental list to synthesis the efficient sensitizers for solar cells.
\end{abstract}

Key words: DSSC, LHE, DFT, 2,1,3-Benzoxadiazole-5-carboxylic acid.

\section{INTRODUCTION}

The direct conversion of sunlight into electrical energy by solar cells is of particular interest because it has many advantages over most presently used electrical power generation methods. In recent years dye-sensitized solar cells (DSSCs), as a novel technology for the conversion of solar energy into electricity, have attracted tremendous and continuous research interest because of easy fabrication, lower cost and relatively higher efficiency compared to other photo voltaic technology. It has been found that all of the main components in DSSCs, including dye sensitizers, anode and cathode as well as electrolyte can affect the photon-to-current conversion efficiency (PCE). Specifically, the dye sensitizers, which have the function of light harvesting and photon exited electron injection, have a significant influence on the $P C E^{1-5}$.

Due to the global challenge in searching and developing renewable energy sources, photo voltaic technologies become a topic of interest in the design of solar to electrical energy conversion cell. Even though multi junction solar cell has been successfully performed in the laboratory scale with up to $40 \%$ conversion efficiency, but their high production cost and toxicity to environment are problem to use as solar electricity in a very large 
scale. The feasibility to develop a solar cell, organic molecules and polymers are two of the most important alternatives ${ }^{6}$.

Currently, molecular modeling techniques and especially quantum chemistry offer a competitive alternative for the interpretation of the experimental data arising from industrial interests and developments. For UV/Vis calculations, one of the most popular approach remains in the timedependent density functional theory (TDDFT), which commonly provides accurate results for a reasonable computational effort, especially when hybrid functional are used. Therefore, we have set up a general TDDFT-based theoretical procedure for the UV/Vis prediction of BCA absorption spectra, and we strive for the 0.1-0.2 eV accuracy that is the generally accepted upper limit required for the design of new industrial dyes. To meet this target, our computational procedure is taking into account the solvation process of the dyes by means of the Polarizable Continuum Model (PCM). This above mentioned procedure is also used to gain insights into the geometrical and electronic structures, of the dyes and to bring up the adequate structural modifications to optimize the properties of the newly designed DSSCs. More precisely, in this contribution, we focus on the free energy of the electron injection onto the $\mathrm{TiO}_{2}$ substrate and on the light harvesting abilities of the dyes ${ }^{7-8}$.

The 2,1,3 Benzoxadiazole-5-carboxylic acid $[B C A]$ belongs to heterocyclic building blocks and also laser dyes. It is widely used in organic electronics and photonics. The molecular formula of the chemical is $\mathrm{C}_{7} \mathrm{H}_{4} \mathrm{~N}_{2} \mathrm{O}_{3}$. It is a hydrogen bond acceptor and donor. As such, we consider it important to understand the similarity between their properties and hope it can be used for DSSC.

\section{Computational details}

All calculations have been performed with the Gaussian 09 package $^{9}$. The ground state geometries of 2,1,3 Benzoxadiazole-5-carboxylic acid dyes optimized with DFT at B3LYP/6$311+G(d, p)$ level $^{10,11}$. The solvation effects were evaluated using Polarizable Continuum Model (PCM). ${ }^{12,13}$. In PCM, one usually divides the problem into a solute part (the dye) lying inside a cavity and a solvent part ${ }^{14-16}$.

\section{RESULTS AND DISCUSSION}

\section{Electronic structure}

This study was carried out to design new sensitizers for DSSC application. The designed dyes consist of following parts: Auxiliary donor (AD), donor (D), pi-spacer $(\sigma)$ and acceptor $(A)$ as shown in Figure 1. We have designed new dyes by the structural modification of 2,1,3 Benzoxadiazole-5carboxylic acid(BCA). Structure of 2,1,3 Benzoxadiazole-5-carboxylic acid(BCA) and its structural modifications are given in Figure 2. The ground state structure for 2,1,3 Benzoxadiazole-5carboxylic acid $(B C A)$ dyes were carried out at the B3LYP- 6-311+G(d,p) level. The discussion based on geometrical parameter of ground state structure is neglected. The highest occupied molecular orbital energies (HOMO) and the lowest unoccupied molecular orbital energies LUMO of all BCA dyes computed at the B3LYP-6311+G(d,p) level in gas phase and DMF are listed in table 1. Both HOMO and LUMO levels for all dyes in solvent medium are higher than that of a gas phase. The energy gap

Table 1: The $E_{\text {номо }}, E_{\text {Lumo }}$ and energy gap (Eg) of dyes in eV at B3LYP/6-311+G level of theory

\begin{tabular}{|c|c|c|c|c|c|c|}
\hline \multirow[b]{2}{*}{ System } & \multicolumn{3}{|c|}{ GASPHASE } & \multicolumn{3}{|c|}{ DMF } \\
\hline & $\mathrm{E}_{\text {номо }}$ & $\mathrm{E}_{\text {Lumo }}$ & $\mathrm{E}_{\text {gap }}$ & $\mathrm{E}_{\text {номо }}$ & $E_{\text {Lumo }}$ & $E_{\text {gap }}$ \\
\hline $\mathrm{BCA}$ & -7.309 & -3.362 & 3.948 & -7.159 & -3.272 & 3.887 \\
\hline $\mathrm{BCA}_{1}$ & -7.007 & -3.551 & 3.456 & -6.854 & -3.373 & 3.484 \\
\hline $\mathrm{BCA}_{2}$ & -5.909 & -3.666 & 2.242 & -5.876 & -3.591 & 2.285 \\
\hline $\mathrm{BCA}_{3}$ & -6.593 & -3.934 & 2.659 & -6.351 & -3.732 & 2.620 \\
\hline $\mathrm{BCA}_{4}$ & -5.831 & -3.221 & 2.611 & -5.876 & -3.106 & 2.769 \\
\hline $\mathrm{BCA}_{5}$ & -4.352 & -3.355 & 0.997 & -4.343 & -3.365 & 0.978 \\
\hline
\end{tabular}


also decreased in DMF except BCA-4. This may be due to the environmental media playing a major role in stabilization of HOMO. However, the least positive value of energy gap in figure 3 shows that the data of HOMO, LUMO energies was extracted from optimization output in gas phase. Figure 4 show the levels of $\mathrm{HOMO}$, LUMO of all the dyes in solvent phase when the frontier molecular orbital of all dyes are compared with the corresponding metal oxide. To get further insights into the molecular structure and electronic distribution of these organic dyes, we have performed the molecular orbital analysis (MOA) at the B3LYP/6-311+G(d,p) level of theory. The electron distribution for the HOMO and LUMO of BCA derivatives are depicted in figure 5. For all the considered systems the HOMO is essentially localized on the nitrogen atoms whereas LUMO is located in anchoring group through $\sigma$-bridge. The MOA reveals that the canon-acrylic acid group is essentially coplanar to the phenyl group. It is also important to underline that in view of the MOA, the $\mathrm{HOMO} \rightarrow$ LUMO excitation induced by light irradiation could move the electron distribution from the BCA moiety to the anchoring group. Therefore, assuming a similar molecular orbital shape when the dye is anchored to the LUMO centered on the anchoring moiety should enhance the orbital overlap with the titanium $3 d$ orbital and subsequently favour the electron injection in $\mathrm{TiO}_{2}$ matrix.

\section{Electron injection}

In this section, we focus on the evaluation of the electro chemical properties of the dyes in

Table 2: Calculated absorption spectra $\lambda_{\max } \mathrm{nm}, \Delta \mathrm{G}^{\text {inject, }}$, oxidation potential, intramolecular charge transfer energy of dyes at B3LYP/6-311+G level of energy

\begin{tabular}{|c|c|c|c|c|c|c|c|c|c|c|}
\hline \multirow[b]{2}{*}{ System } & \multicolumn{5}{|c|}{ GAS PHASE } & \multicolumn{5}{|c|}{ DMF } \\
\hline & $\lambda_{\max }(\mathrm{nm})$ & $\Delta G^{\text {inject }}$ & $\mathbf{E}_{\text {ox }}^{\text {dye }}$ & $E_{\text {ox }}^{\text {dye }}$ & $\lambda_{\text {max }}^{\text {ICT }}$ & $\lambda_{\max }(\mathrm{nm})$ & $\Delta G^{\text {inject }}$ & $\mathbf{E}^{\mathrm{dye}^{*}}{ }_{\text {ox }}$ & $\mathrm{E}_{\text {ox }}^{\text {dye }}$ & $\lambda_{\text {max }}^{\text {ICT }}$ \\
\hline $\mathrm{BCA}$ & 296.01 & -0.880 & 3.120 & 7.309 & 4.189 & 293.61 & -1.064 & 2.936 & 7.159 & 4.223 \\
\hline BCA1 & 349.35 & -0.542 & 3.458 & 7.007 & 3.549 & 361.10 & -0.580 & 3.420 & 6.854 & 3.434 \\
\hline BCA2 & 443.20 & -0.888 & 3.112 & 5.909 & 2.797 & 449.40 & -0.883 & 3.117 & 5.876 & 2.759 \\
\hline BCA3 & 381.05 & -0.661 & 3.339 & 6.593 & 3.254 & 386.80 & -0.854 & 3.146 & 6.351 & 3.205 \\
\hline BCA4 & 450.10 & -0.924 & 3.076 & 5.831 & 2.755 & 431.51 & -0.997 & 3.003 & 5.876 & 2.873 \\
\hline BCA5 & 853.80 & -1.100 & 2.900 & 4.352 & 1.452 & 842.98 & -1.128 & 2.872 & 4.343 & 1.471 \\
\hline
\end{tabular}

Table 3: Excitation energy (E), Light Harvesting Efficiency (LHE) and Average Light Harvesting Efficiency $\left(\right.$ LHF $_{\text {Average }}$ ) of dyes at B3LYP/6-311+G level of theory

\begin{tabular}{|c|c|c|c|c|c|c|c|c|}
\hline \multirow[b]{2}{*}{ System } & \multicolumn{3}{|c|}{ GASPHASE } & \multirow[b]{2}{*}{ LHE $_{\text {avg }}$} & \multirow[b]{2}{*}{$E(e V)$} & \multicolumn{3}{|c|}{ DMF } \\
\hline & $E(e V)$ & $\lambda(\mathrm{nm})$ & LHE & & & $\lambda(\mathrm{nm})$ & LHE & LHE $_{\text {avg }}$ \\
\hline \multirow[t]{2}{*}{$\mathrm{BCA}$} & 4.189 & 296.01 & 0.001 & 0.029 & 4.223 & 293.60 & 0.001 & 0.040 \\
\hline & 4.363 & 284.17 & 0.056 & & 4.363 & 284.16 & 0.079 & \\
\hline \multirow{2}{*}{$\mathrm{BCA}_{1}$} & 3.549 & 349.35 & 0.068 & 0.057 & 3.434 & 361.10 & 0.103 & 0.295 \\
\hline & 4.112 & 301.54 & 0.045 & & 4.122 & 300.81 & 0.486 & \\
\hline \multirow[t]{2}{*}{$\mathrm{BCA}_{2}$} & 2.790 & 443.20 & 0.072 & 0.166 & 2.759 & 449.40 & 0.097 & 0.206 \\
\hline & 3.055 & 405.88 & 0.260 & & 3.032 & 408.99 & 0.314 & \\
\hline \multirow[t]{2}{*}{$\mathrm{BCA}_{3}$} & 3.254 & 381.05 & 0.180 & 0.136 & 3.205 & 386.80 & 0.183 & 0.151 \\
\hline & 3.418 & 362.74 & 0.091 & & 3.307 & 374.87 & 0.119 & \\
\hline \multirow[t]{2}{*}{$\mathrm{BCA}_{4}$} & 2.755 & 450.10 & 0.156 & 0.160 & 2.873 & 431.50 & 0.156 & 0.185 \\
\hline & 3.337 & 371.58 & 0.163 & & 3.219 & 385.12 & 0.213 & \\
\hline \multirow[t]{2}{*}{$\mathrm{BCA}_{5}$} & 1.452 & 853.80 & 0.002 & 0.007 & 1.471 & 843.00 & 0.005 & 0.036 \\
\hline & 1.795 & 690.80 & 0.012 & & 1.786 & 694.30 & 0.067 & \\
\hline
\end{tabular}


their excited state. More precisely, we propose to establish a reliable theoretical scheme to quantify the electron injection onto a Titanium Dioxide $\left(\mathrm{TiO}_{2}\right)$ surface for selected BCA derivatives ${ }^{17-19}$.

The free energy change (in $\mathrm{eV}$ ) for the electron injection can be expressed as

$$
\Delta \mathrm{G}^{\text {inject }}=\mathrm{E}^{\text {dye }}{ }_{\mathrm{ox}}^{*}-\mathrm{E}_{\mathrm{CB}}^{\mathrm{SC}}
$$

Where $E^{\text {dye }}{ }^{*}$ is the oxidation potential of the dye in the excited state, and $\mathrm{E}_{\mathrm{CB}}^{\mathrm{SC}}$ is the reduction potential of the conduction band of the semiconductor. It is often difficult to accurately determine $\mathrm{E}^{\mathrm{SC}}{ }_{C B}$ experimentally because it is sensitive to the surface conditions, as well as to the $\mathrm{pH}$ of the solution. Nevertheless, the $\mathrm{E}_{\mathrm{CB}}^{\mathrm{SC}}$ values of several materials have been reported, and have been using $\mathrm{E}_{C \mathrm{CB}}^{\mathrm{SC}}-4.0 \mathrm{eV}$ for $\mathrm{TiO}_{2}$. The presented value has been experimentally determined and refers to conditions where the semiconductor is in contact with aqueous redox electrolytes of fixed $\mathrm{pH}$.
In table 2, we provide the electron injection free energy $\left(\Delta G^{\text {inject }}\right)$, ground [ $\left.E^{\text {dye }}{ }_{\text {ox }}\right]$ and excited $\left[\mathrm{E}^{\mathrm{dye}} \mathrm{ox}^{*}\right]$ state oxidation potential computed in gas phase and solvent phases for the series of BCA dyes. From these results one can conclude that the effects of the dielectric surroundings on $\Delta G^{\text {inject }}$ value is huge with the shift of approximately $-0.2 \mathrm{eV}$ when going from gas to DMF. Note that the shift of the both ground and excited state oxidation potential in solvent phase reduce which results in the stabilization of oxidized dyes and favour the electron injection in solvent medium. A comparison between gas and solvent phase oxidation potential allows to conclude that the ground state oxidation potential cathodic shift induced by the solvent is only loosely sensitive to the permittivity of the surroundings. All $\Delta G^{\text {inject }}$ estimated in the table 2 is a negative value for all dyes. More negative of $\Delta G^{\text {inject }}$ from gas to solvent medium were found. From these results, it is indicated that the effect of dielectric surroundings to $\Delta G^{\text {inject }}$ values is huge with a shift of $-0.18 \mathrm{eV}$ from gas to solvent.

Table 4: Oscillator strength (f) and Transition character of dyes (H=HOMO L=LUMO, $L+1=L U M O+1$, etc) at B3LYP/6-311+G level of theory (Major contribution in Paranthesis)

\begin{tabular}{|c|c|c|c|c|c|c|}
\hline \multirow[b]{2}{*}{ System } & \multicolumn{3}{|c|}{ GASPHASE } & \multicolumn{3}{|c|}{ DMF } \\
\hline & $\lambda(\mathrm{nm})$ & (f) & $\begin{array}{l}\text { Transition } \\
\text { Character }\end{array}$ & $\lambda(\mathrm{nm})$ & (f) & $\begin{array}{l}\text { Transition } \\
\text { Character }\end{array}$ \\
\hline \multirow[t]{3}{*}{$\mathrm{BCA}$} & 354.86 & 0.035 & $\mathrm{H} \rightarrow \mathrm{L}(100 \%)$ & 367.49 & 0.044 & $\mathrm{H} \rightarrow \mathrm{L}(100 \%)$ \\
\hline & 296.01 & 0.000 & $\mathrm{H}-1 \rightarrow \mathrm{L}(78 \%)$ & 293.61 & 0.000 & $\mathrm{H}-1 \rightarrow \mathrm{L}(76.6 \%)$ \\
\hline & 284.17 & 0.025 & $\mathrm{H}-2 \rightarrow \mathrm{L}(77 \%)$ & 284.16 & 0.036 & $\mathrm{H}-2 \rightarrow \mathrm{L}(76 \%)$ \\
\hline \multirow[t]{3}{*}{$\mathrm{BCA}_{1}$} & 400.47 & 0.221 & $\mathrm{H} \rightarrow \mathrm{L}(100 \%)$ & 404.67 & 0.328 & $\mathrm{H} \rightarrow \mathrm{L}(100 \%)$ \\
\hline & 349.35 & 0.031 & $\mathrm{H}-1 \rightarrow \mathrm{L}(83 \%)$ & 361.1 & 0.047 & $\mathrm{H}-1 \rightarrow \mathrm{L}(86.4 \%)$ \\
\hline & 301.54 & 0.020 & $\mathrm{H} \rightarrow \mathrm{L}+1 \quad(74 \%)$ & 300.81 & 0.289 & $\mathrm{H} \rightarrow \mathrm{L}+1(74.5 \%)$ \\
\hline \multirow[t]{3}{*}{$\mathrm{BCA}_{2}$} & 600.06 & 0.228 & $\mathrm{H} \rightarrow \mathrm{L} \quad(100 \%)$ & 619.41 & 0.291 & $\mathrm{H} \rightarrow \mathrm{L}(100 \%)$ \\
\hline & 443.21 & 0.032 & $\mathrm{H}-1 \rightarrow \mathrm{L}(69 \%)$ & 449.4 & 0.044 & $\mathrm{H}-1 \rightarrow \mathrm{L}(70.8 \%)$ \\
\hline & 405.88 & 0.131 & $\mathrm{H} \rightarrow \mathrm{L}+1 \quad(62 \%)$ & 408.99 & 0.163 & $\mathrm{H} \rightarrow \mathrm{L}+1(63.5 \%)$ \\
\hline \multirow[t]{3}{*}{$\mathrm{BCA}_{3}$} & 489.4 & 0.263 & $\mathrm{H} \rightarrow \mathrm{L}(100 \%)$ & 516.23 & 0.374 & $\mathrm{H} \rightarrow \mathrm{L} \quad(100 \%)$ \\
\hline & 381.05 & 0.086 & $\mathrm{H} \rightarrow \mathrm{L}+1 \quad(71 \%)$ & 386.8 & 0.088 & $\mathrm{H} \rightarrow \mathrm{L}+1 \quad(68.6 \%)$ \\
\hline & 362.74 & 0.041 & $\mathrm{H}-1 \rightarrow \mathrm{L}(65 \%)$ & 374.87 & 0.055 & $\mathrm{H}-1 \rightarrow \mathrm{L}(66 \%)$ \\
\hline \multirow[t]{3}{*}{$\mathrm{BCA}_{4}$} & 569.56 & 0.103 & $\mathrm{H} \rightarrow \mathrm{L}(100 \%)$ & 548.58 & 0.146 & $\mathrm{H} \rightarrow \mathrm{L}(100 \%)$ \\
\hline & 450.07 & 0.074 & $\mathrm{H} \rightarrow \mathrm{L}+1 \quad(79 \%)$ & 431.51 & 0.074 & $\mathrm{H} \rightarrow \mathrm{L}+1 \quad(79.8 \%)$ \\
\hline & 371.58 & 0.078 & $\mathrm{H}-1 \rightarrow \mathrm{L}(67 \%)$ & 385.12 & 0.104 & $\mathrm{H}-1 \rightarrow \mathrm{L}(72.7 \%)$ \\
\hline \multirow[t]{3}{*}{$\mathrm{BCA}_{5}$} & 4045.44 & 0.002 & $\mathrm{H} \rightarrow \mathrm{L}(100 \%)$ & 4486.76 & 0.002 & $\mathrm{H} \rightarrow \mathrm{L}(100 \%)$ \\
\hline & 853.83 & 0.001 & $\mathrm{H} \rightarrow \mathrm{L}+1 \quad(43 \%)$ & 842.98 & 0.002 & $\mathrm{H} \rightarrow \mathrm{L}+1 \quad(42 \%)$ \\
\hline & 690.81 & 0.005 & $\mathrm{H}-1 \rightarrow \mathrm{L}(42 \%)$ & 694.27 & 0.030 & $\mathrm{H}-1 \rightarrow \mathrm{L}(42 \%)$ \\
\hline
\end{tabular}


Light harvesting efficiency (LHE) and oscillator strength

In the present section, we propose structural modifications improving the electron injection efficiency of the BCA based DSSCs. Of course, all modifications are theoretically possible and a large panel of new structure can be tested. We focus on three properties that can be optimized (i) the free energy of injection $\Delta G^{\text {inject. }}$. (ii) the oxidation potential of the dyes must be more positive, (iii) the light harvesting efficiency (LHE) of the dye has to be as high as possible to maximize the photocurrent response. More precisely, LHE is expressed $\mathrm{as}^{20}$

$\mathrm{LHE}=1-10^{-\mathrm{A}}=1-10^{-\mathrm{f}}$

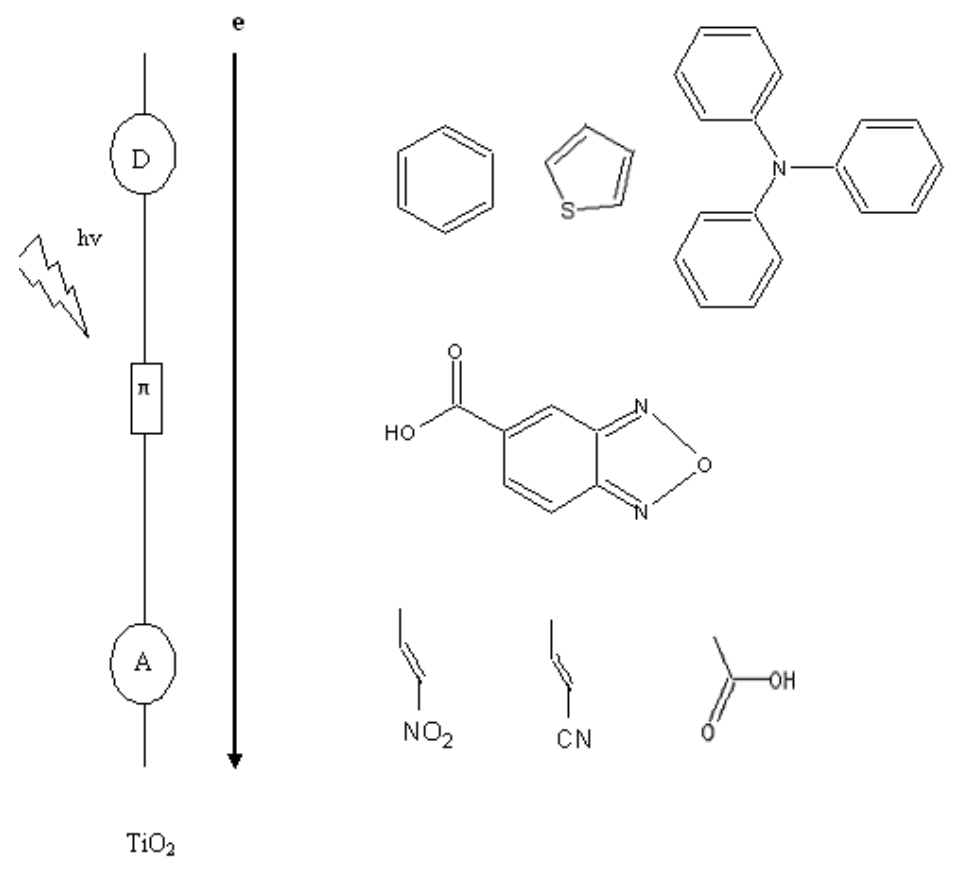

Fig. 1: Different parts of $D-\Delta-A$ system. $D=$ donor, $\pi=$ pi-spacer, $A=$ acceptor<smiles>O=C(O)c1ccc2nonc2c1</smiles><smiles>[R1]C=Cc1c(C(=O)O)cc([R2])c2nonc12</smiles>
BCA-1 R1 $=$ CN
$\mathrm{R} 2=\mathrm{C}_{6} \mathrm{H}_{6}$;
BCA-2 R1 $=\mathrm{NO}_{2} \mathrm{R} 2=\mathrm{C}_{6} \mathrm{H}_{6}$
$B C A-3 \quad R 1=C N$
$\mathrm{R} 2=\mathrm{C}_{4} \mathrm{H}_{4} \mathrm{~S}$
;
BCA-4 R1 $=\mathrm{NO}_{2} \mathrm{R} 2=\mathrm{C}_{4} \mathrm{H}_{4} \mathrm{~S}$
$\mathrm{BCA}-5 \quad \mathrm{R} 1=\mathrm{CN}$
$\mathrm{R} 2=\mathrm{C}_{18} \mathrm{H}_{15} \mathrm{~N}$

Fig. 2: Chemical Structure of 2,1,3 Benzoxadiazole-5-carboxylic acid [BCA] newly designed dyes 
Where $A(f)$ is the absorption (oscillator strength) of the dye associated to the $\lambda_{\text {max }}$. It is known that TDDFT is less efficient for the evaluation of transition probabilities than for transition energies. For the sake of computational consistency, the LHE criterion has therefore to be underweighted in our classification, as our estimates of $\Delta \mathrm{G}^{\text {inject }}$ and $\mathrm{E}^{\text {dye }}$ ox are probably more reliable. However, we have to underline that the dependence of the experimental extinction coefficient with respect to auxochromic effects was qualitatively reproduced for the 2,1,3 Benzoxadiazole-5-Carboxylic acid derivatives.

The light harvesting efficiency (LHE) is the efficiency of dye in responding to light .It is another factor which indicates the efficiency of DSSC. The light harvesting efficiency (LHE) of the dye should be as high as possible to maximize the photocurrent response. The value of LHE of the dyes has to be as high as possible to maximize the photocurrent response. The LHE has to be underweighted for the calculation. These values are important for charge transfer process in DSSC. So the LHE is regarded to underweight in this work. The LHE of all the dyes are calculated and listed in table 3. The LHE of all the dyes fall within the range of 0.007-0.166 in gas phase and 0.036-0.295 in gas to DMF. The LHE values for the dyes are in a narrow range. This means that all the dyes will give similar photocurrent. It can be concluded that a class of selected BCA

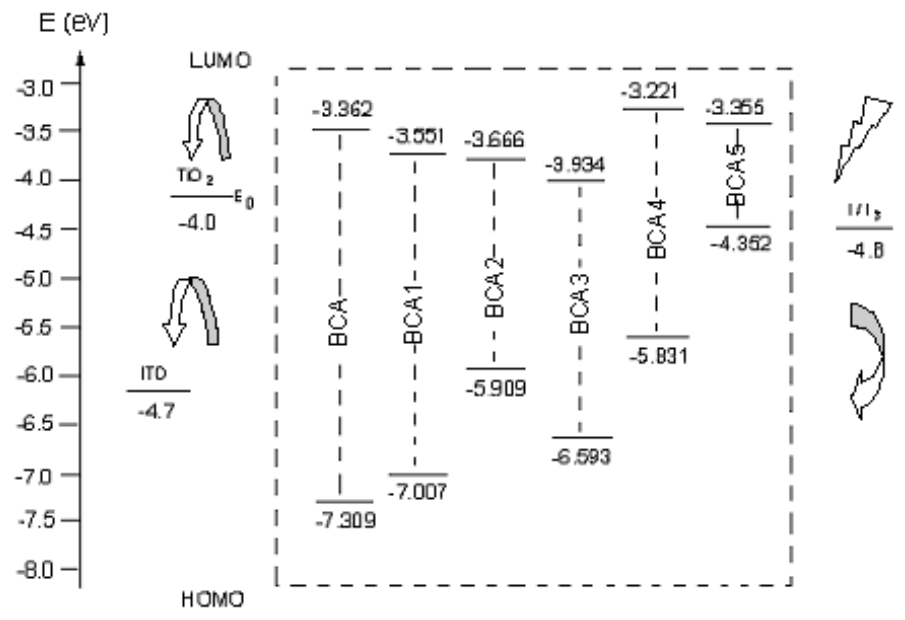

Fig. 3: Schematic energy diagram of dyes, $\mathrm{TiO}_{2}$ and electrolyte $\left(1 / I_{3}\right) . \mathrm{E}_{\text {номо }}$ and $\mathrm{E}_{\mathrm{Lumo}}$ of the dyes are in gas phase

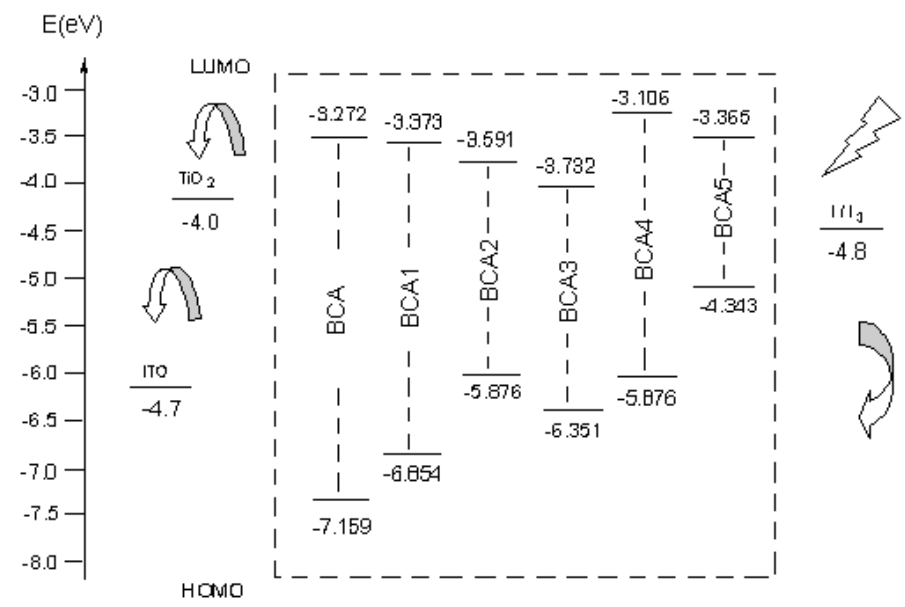

Fig. 4: Schematic energy diagram of dyes, $\mathrm{TiO}_{2}$ and electrolyte $\left(\mathrm{II/} \mathrm{I}_{3}\right) \cdot \mathrm{E}_{\mathrm{Hомо}}$ and $\mathrm{E}_{\mathrm{Luмо}}$ of the dyes are in DMF 
derivative dyes shows a good photo physical properties related to DSSC use but in different outstanding properties. According to LHE, BCA3 in gas phase and BCA2 in DMF phase are the most efficient than that of the other derivatives studied here. From this we can assume that substitutes of acceptor and donor atoms can enrich the properties of BCA derivatives dyes for the use in DSSC.

The oscillator strength is directly obtained from DFT calculations. The BCA dye has two main absorption peaks [355 and $296 \mathrm{~nm}$ in gas phase, 293 and $284 \mathrm{~nm}$ in solvent phase DMF].Higher oscillator strength of the four new designed sensitizers than that of BCA is as shown in table 3.These dyes will convert more light to electrical energy. The oscillator strength and transition character are given in table 4.Only the transition with considerable oscillator strengths are given. The electron structure of the four new designed sensitizers is quite similar to one another.
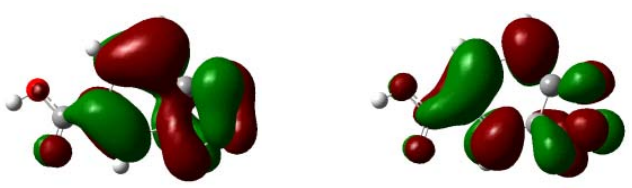

BCA HOMO

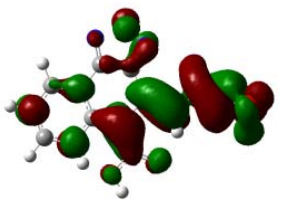

BCA2HOMO

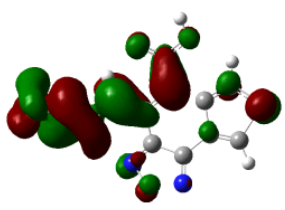

BCA4 HOMO

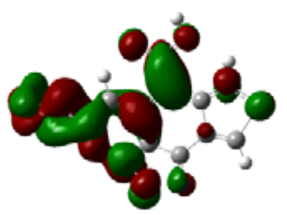

BCA4 LUMO

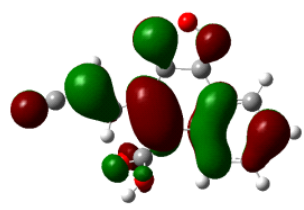

BCA1HOMO

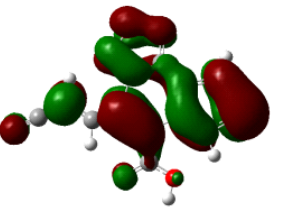

BCA3HOMO

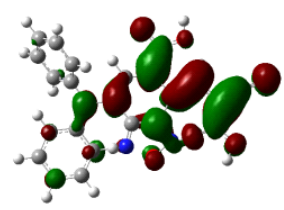

BCA5 HOMO

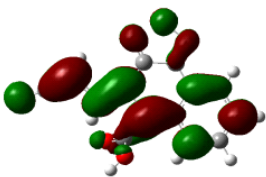

BCA1LUMO

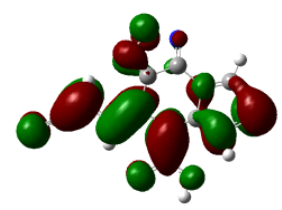

BCA3LUMO

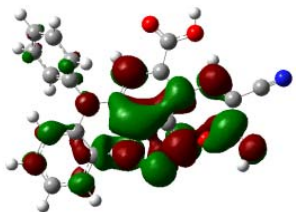

BCA5 LUMO

Fig. 5: The HOMO and LUMO distribution pattern of dyes at B3LYP/6-311+G level of theory
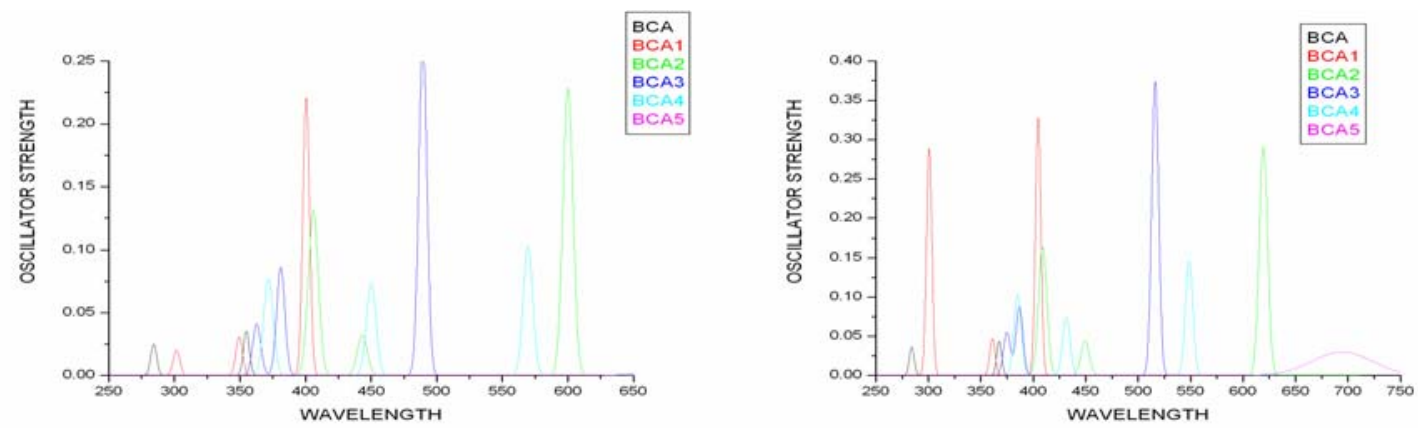

Fig. 6: Simulated absorption spectra of dyes calculated in Gas phase and DMF at B3LYP/6-311+G level of theory 
Improve $\Delta \mathrm{G}^{\text {inject }}$ and $\mathrm{LHE}$ of new designed sensitizers as compared to BCA is due to the addition of acceptor and donor molecules. In the benzene ring this can be considerable by the distribution pattern of HOMO and LUMO of BCA derivatives. It encourages the promotion of electron injection.

\section{Electronic absorption spectra}

TD/DFT/6-311+G(d,p) methods were employed to simulate the optical properties of the dyes. The computed vertical excited singlet states, transition energies and oscillating strength of all dyes in gas phase and solvent medium are tabulated in table 4.The graph plotted wavelength versus oscillator strength are shown in figure 6 .

The vertical excitation energies of the dyes are increasing $\Delta \mathrm{E}_{\text {exi }}$ its value by the substitution. The transition to the character of most of the dyes show the HOMO, LUMO transition as the first singlet excitation except for BCA. In the major contribution of the transition characters in the gas phase differs from those solvent due to the effect of polar environment and the electronic energy level. The maximum wavelength for UV-Vis absorption spectra of all the dyes simulated in various media are shown in table 4.The calculation in gas phase and solvent medium is different by approximately the red shift were found for most of the dyes from gas phase and solvent phase.

\section{CONCLUSION}

This work is reported as a theoretical study of 2,1,3 Benzoxadiazole-5-carboxylic acid dye using DFT method. The ground and the excited state oxidation potential energy as well as electron injection of the dyes show that these dyes are potential to be good photo sensitizers in DSSC. The LUMO of the dyes with nearly $1.0 \mathrm{eV}$ upper than $\mathrm{E}_{\mathrm{cb}}$ of $\mathrm{TiO}_{2}$ indicated that these dyes are thermodynamically favorable in charge transfer into conduction band of $\mathrm{TiO}_{2}$. All new designed dyes were highly red shifted as compared to $2,1,3$ Benzoxadiazole-5-carboxylic acid due to solvent effect. It can be noted that on the BSC dyes in this calculations give the better DSSC efficiency. However we suggest that the further chemical modification of the dye such as adding high effective electron acceptors and donors could raise the $\Delta G^{\text {inject }}$ and LHE of the DSSC with these photo sensitizers.

\section{REFERENCES}

1. Austin Suthanthiraraj.S,Indian Journal of Pune and applied physics 2013., 51.,310314.

2. Francisco Cervantes-Navarro, Daniel Glossman-Mitnik, Journal of Photochemistry and Photobiology A: Chemistry 2013., 255 ., 24-26.

3. Kamat. P.V, Haria.M, Hotchandani.S, J. Phys. Chem. 2004., 108,.5166.

4. Bisquert.J, Cahen.D, Hodes.G, Ruehie.S, Zaban.A, J. Phys. Chem. 2004.,108 8106.

5. Furube.A, Katoh.R, Yoshihara.T, Hara.K, Murata.S, Arakawa.H, Tachiya.M, J. Phys. Chem.. 2004 .,108, 12588.

6. Gratzel.M, Recent advances in sensitized mesoscopic Solar Cells, Acc. Chem. Res. 2009 .,42 1788-1798.

7. Serrann.L - Andres, Roos.B.O, A theoretical study of the indigoid dyes and their chromophore, Chemistry - A European Journal 1997 ., 3 .,717-725.

8. Susse.P, Steins.M, V. Indigo Crystal Structure refinement based on synchrotron data, Zeitschrift fur Kristallograhie 1988 .,184 269273.

9. Gaussian 09 Program, Revision C.01, Frisch.J, Trucks.G.W, .Schlegel.H.B, Scuseria.G.E, Robb.M.A, Cheeseman.J.R, Scalmani.G, Barone.V, Mennucci.B, Petersson.G.A, Nakatsuji.H, Caricato.M, Li.X, Hratchian.H.P, Izmaylov.A.F, Bloino.J, Zheng.G, Sonnenberg.J.L, Hada.M, Ehara.M, Toyota.K, Fukuda.R, Hasegawa.J, Ishida.M, Nakajima.T, Honda.Y, Kitao.O, Nakai.H, Vreven.T, Montgomery.J.A, Jr., Peralta.J.E, Ogliaro.F, Bearpark.M, Heyd.J.J, Brothers.E, Kudin.K.N, Staroverov.V.N, Keith.T, Kobayashi.R, Normand.J, 
Raghavachari.K, Rendell.A, Burant.J.C, lyengar.S.S, Tomasi.J, Cossi.M, Rega.N, Millam.J.M, Klene.M, Knox.J.E, Cross.J.B, Bakken.V, Adamo.C, Jaramillo.J, Gomperts.R, Stratmann.R.E, Yazyev.O, Austin.A.J, Cammi.R, Pomelli.C, Ochterski.J.W, Martin.R.L, Morokuma.K, Zakrzewski.V.G, Voth.G.A, Salvador.P, Dannenberg.J.J, Dapprich.S, Daniels.A.D, Farkas.O, Foresman.J.B, Ortiz.J.V, Cioslowski.J, and Fox.D.J, Gaussian, Inc., Wallingford $C T, 2010$.

10. Becke.A.D, J. Chem. Phys. 1993., 98 .,1372.

11. Lee.C, Yang.W, Parr.R.G, Phys. Rev. B .,1988.,37., 785.

12. Tomsi.J, Mennucci.B, Cances.E.T, J. Mol. Structure THEOCHEM. . 1999,464 .,211.

13. Cossi.M, Barone.V, J. Chem. Phys. .
1998,109.6264.

14. Cossi.M, Barone.V, J. Chem. Phys. 2001., 1154708.

15. Amovilli.C, Barone.V, Cammi.R, Cances.E, Cossi.M, Mennucci.B, Pomelli.C.S, Tomasi.J, Adv. Quantum Chem. .,1998.,32., 227.

16. Tomasi.J, Mennucci.B, Cammi.R, Chem. Rev. 2005., 105 .,2999.

17. Kotob.R, Furube.A, Yoshihara.T, Hara.K, Fujihashi.G, Takano.S, Murata.S, Arakawa.H, Tachiya.M, J. Phys. Chem. B 2004, 108. 4818.

18. Rehm.D, Weller.A, Isr. J. Chem. 1970 .,8 ,259.

19. Goodman.J.I, Peters.K.S, J. Am. Chem. Soc. 1986 , 108, 1700.

20. Nalwa .H.S, Handbook of Advanced Electronic and Photonic Materials and Devices; Academic: San Diego. (2001). 